\title{
PENINGKATKAN KEMAMPUAN KONEKSI MATEMATIS DAN KEMANDIRIAN BELAJAR SISWA MELALUI PENDEKATAN OPEN-ENDED
}

\author{
Alpha Galih Adirakasiwi \\ Pendidikan Matematika, Universitas Singaperbangsa Karawang \\ E-mail : alphagalih@fkip.unsika.ac.id
}

Received 30 August 2018; Received in revised form 18 September 2018; Accepted 24 September 2018

\begin{abstract}
This study aims to analyze the enhancement of mathematical connection ability and self-study of senior high school students through an open-ended approach. The research method used in this study was a mixed method with embedded type and a quasi-experimental design. The populations of this study were all students of public senior high schools in Karawang. Furthermore, the sample of this study was the tenth-grade students. Samples were taken by purposive sampling technique. Data in this study was collected by mathematical connection ability test and self-study test. The results are: 1) the achievement and enhancement of mathematical connection ability of students that use an open-ended approach is better than students who use conventional learning; 2) self-study of students that use an open-ended approach is better than students who use conventional learning; 3) there is a significant association between the qualification of students' mathematical connection ability and students' self-study. Based on the results of the study, it can be concluded that students and teachers need a learning that can stimulate students' intellectual abilities and experiences in the process of finding something new.
\end{abstract}

Keywords: learning independence; mathematical connection; open-ended approach

\section{PENDAHULUAN}

Kemampuan menyelesaikan masalah dalam pembelajaran matematika merupakan salah satu kompetensi dasar yang harus dimiliki siswa dalam pembelajaran matematika di sekolah. Menurut National Council of Teacher of Mathematics atau NCTM (Kurniawan dalam Siagian, 2016) menyatakan bahwa standar matematika sekolah harus meliputi standar isi dan proses. Standar proses meliputi: (1) penyelesaian masalah (problem solving); (2) penalaran dan pembuktian (reasoning and proof); 3) komunikasi (communication); (connection); dan representasi (represenation). Dalam rangka untuk mengembangkan koneksi matematis, Harnisch dalam Qohar (2011), mengemukakan 3 macam koneksi yang harus dikembangkan, yaitu: (1) data connection, yaitu ide-ide matematika dikoneksikan dengan ide dalam science, misalkan "log" dalam math dihubungkan dengan $\mathrm{pH}$ dalam kimia. (2) language connection, yaitu bahasa yang umum digunakan dalam matematika dikaitkan dengan bahasa yang digunakan dalam sains, misalnya penggunaan satuan panjang $\mathrm{cm}, \mathrm{cm} 2$, dll. (3) life connection, yaitu matematika dan science dihubungkan

Aspek yang tak kalah penting yaitu aspek koneksi matematik. (Sumarmo, 2013) mengatakan bahwa koneksi matematik meliputi indikatorindikator berikut mencari hubungan berbagai representasi konsep dan prosedur, memahami hubungan antar topik matematika, menggunakan matematika dalam bidang studi lain atau kehidupan sehari-hari, memahami representasi ekuivalen konsep yang sama, mencari koneksi dari satu prosedur lain dalam representasi ekuivalen, menggunakan koneksi antar topic matematika dan koneksi antar topik matematika dengan topik lain. 
Melaui koneksi matematik, konsep pemikiran dan wawasan siswa akan semakin terbuka terhadap matematika, tidak hanya berfokus pada topik tertentu yang sedang dipelajari. Membuat koneksi merupakan standard yang jelas dalam pendidikan matematika yang juga menjadi salah satu standard utama yang disarankan
Kemampuan

koneksi matematis merupakan kemampuan dasar matematis yang harus dikuasai siswa sekolah menengah. Namun, hasil belajar matematika siswa selama ini masih rendah, khususnya dalam aspek koneksi matematis. Dilihat dari hasil ulangan harian pada materi trigonometri dengan menggunakan indikator kemampuan koneksi matematis

Tabel 1. Data ulangan harian kemampuan koneksi matematis

\begin{tabular}{clc}
\hline $\begin{array}{c}\text { Nomor } \\
\text { Soal }\end{array}$ & \multicolumn{1}{c}{$\begin{array}{c}\text { Indikator } \\
\text { Kemampuan Koneksi Matematis }\end{array}$} & $\begin{array}{c}\text { Rerata } \\
\text { Persentase (\%) }\end{array}$ \\
\hline $\mathbf{1}$ & $\begin{array}{l}\text { Mencari hubungan antar berbagai representasi konsep dan } \\
\text { prosedur serta memahami hubungan antar topik matematika }\end{array}$ & 31.11 \\
\hline $\mathbf{2}$ & $\begin{array}{l}\text { Memahami representasi ekuivalen konsep yang sama, } \\
\text { mencari koneksi satu prosedur ke prosedur lain dalam } \\
\text { represetasi ekuivalen }\end{array}$ & 24.05 \\
\hline $\mathbf{3}$ & $\begin{array}{l}\text { Mencari hubungan berbagai representasi konsep dan prosedur } \\
\text { Menggunakan matematika dalam bidang studi lain atau }\end{array}$ & 18.87 \\
\hline $\mathbf{4}$ & $\begin{array}{l}\text { kehidupan sehari-hari } \\
\text { 5. }\end{array}$ & $\begin{array}{l}\text { Menggunakan dan menilai keterkaitan antar topik matematika } \\
\text { dan keterkaitan topik matematika dengan topik diluar } \\
\text { matematika }\end{array}$ \\
\hline
\end{tabular}

$\begin{array}{cll}\text { Hasil } & \text { ulangan harian dengan } \\ \text { indikator } & \text { kemampuan } & \text { koneksi }\end{array}$ matematis masih rendah. Sesuai dengan penelitian Ruspiani (Isfayani dkk, 2018) yang menunjukkan nilai rata-rata kemampuan koneksi siswa sekolah menengah masih rendah yaitu kurang dari 60 pada skor $100(22,2 \%$ untuk koneksi matematika pada pokok bahasan lain, 44\% untuk koneksi bidang studilain Dan 67,3\% untuk koneksi matematika pada kehidupan seharihari). Begitu pula dengan hasil penelitian Kusuma (Yuniawatika, 2011) yang menyatakan bahwa tingkat kemampuan koneksi matematis siswa SMP masih rendah. Hasil penelitian tersebut menunjukkan bahwa jumlah siswa yang memiliki kemampuan koneksi tinggi masih rendah untuk setiap jenisnya.
Salah satu faktor dikarenakan model pembelajaran matematika kurang mendorong siswa berinteraksi dengan sesama siswa dalam belajar, dan kurang mendorong siswa menggunakan penalaran. Hal ini diperkuat dengan wawancara guru matematika bahwa guru masih menggunakan pembelajaran yang searah. Dilihat dari siswa mengerjakan soal kemampuan koneksi matematis, siswa masih belum terbiasa dengan soal-soal yang bervariasi. Hal ini menyebabkan rendahnya prestasi belajar siswa.

Pada dasarnya, semua siswa memiliki potensi untuk mencapai kompetensi. Jika sampai mereka tidak mencapai kompetensi, bukan karena mereka tidak memiliki kemampuan untuk itu, tetapi lebih banyak karena mereka tidak disediakan pengalaman belajar yang relevan dengan keunikan 
masing-masing karakteristik individual (Muslich, 2008). Guru berperan sebagai fasilitator dalam mengembangkan kemandirian di sekolah. Guru yang mendukung perkembangan kemandirian siswa akan menerapkan cara belajar yang memberikan kebebasan pada siswa untuk memiliki pendapat saat proses belajar di dalam kelas. Kebebasan yang diberikan oleh guru kepada siswa dapat diwujudkan melalui kebebasan dalam mengerjakan tugas sekolah dengan caracara yang disukai siswa.

Kemandirian belajar siswa merupakan kegiatan belajar dengan penuh tanggung jawab dan inisiatif sendiri, baik dilakukan secara sendiri maupun berkelompok. Hal ini akan ditunjukkan siswa tersebut melalui tingkah laku dalam mengerjakan setiap tugas sekolah, ia akan berusaha mengerjakan tugas sebaik mungkin dengan mencari dari berbagai sumber, seperti : bertanya pada guru, membaca buku, membaca internet ataupun referensi lainnya. Sebagaimana yang dikemukan oleh Steinberg (dikutip Fleming, 2005, h.2) bahwa kemandirian belajar didefinisikan sebagai kemampuan dalam bertingkah laku, merasakan sesuatu, dan mengambil keputusan berdasar kehendaknya sendiri.

Kemandirian dalam belajar memerlukan tanggung jawab. Tanggung jawab merupakan sikap yang perlu dimiliki oleh setiap siswa. Tanggung jawab seorang siswa adalah belajar dan mengerjakan tugas yang diberikan oleh guru dengan penuh kesadaran. Tanggung jawab yang dimiliki membuat siswa mengerti pentingnya tugas yang diberikan oleh guru. Dengan tugas yang guru berikan, terutama tugas matematika yang mampu membantu siswa memahami materi, serta melatih siswa dalam mengerjakan soal-soal matematika. Hal ini menjadikan siswa semakin terlatih dan mahir dalam mengaplikasikan rumus dengan permasalahan yang terdapat di dalam soal. Sikap dan kebiasaan berpikir yang baik pada hakekatnya akan membentuk dan menumbuhkan kemandirian belajar.

Upaya untuk meningkatkan kemampuan koneksi matematis dan kemandirian belajar dengan menciptakan pembelajaran matematika yang inovatif, melibatkan aspek kognitif, afektif dan psikomotor. Agar dapat lebih mengoptimalkan kemampaun berpikir matematis siswa, guru dapat merancang proses pembelajaran yang melibatkan siswa secara aktif. Guru melibatkan aktifitas aktif siswa selama proses belajar mengajar dan menciptakan materi ajar yang memiliki pertanyaan divergen. Banyak guru matematika yang kesulitan untuk membelajarkan siswanya dalam menyelesaikan problem matematika. Kesulitan itu disebabkan oleh pandangan yang mengatakan bahwa jawaban akhir dari problem merupakan tujuan utama. Pembahasan dengan pendekatan open ended adalah salah satu metode yang dapat menjawab kesulitan-kesulitan yang dihadapi oleh pengajar dan siswa. Pendekatan ini dimaksudkan agar guru-guru dapat memahami lebih jauh bagaimana menyusun soal dan menerapkannya dalam proses pembelajaran matematika sehari-hari di dalam kelas.

Berdasarkan latar belakang masalah, maka yang menjadi tujuan dalam penelitian ini adalah sebagai berikut: untuk memperoleh gambaran tentang (1) pencapaian dan peningkatan kemampuan koneksi matematis serta kemandirian belajar siswa yang memperoleh pendekatan open-ended lebih baik daripada yang memperoleh pembelajaran konvensional; (2) asosiasi antara kemampuan koneksi matematis siswa dengan kemandirian belajar 


\section{METODE PENELITIAN}

Berdasarkan permasalahan di atas telah dilakukan penelitian dengan menggunakan metode campuran (mixed method) ) tipe embedded dengan desain kuasi eksperimen yaitu metode yang tidak memungkinkan peneliti melakukan pengontrolan penuh terhadap variabel dan kondisi eksperimen. Subjek penelitian ini tidak dikelompokkan secara acak. Dalam penelitian sampel yang digunakan terdiri dua kelompok yaitu kelompok kontrol dan eksperimen, dimana pada setiap kelompok diterapkan pembelajaran yang berbeda. Populasi penelitian ini adalah semua siswa kelas $X$ di salah satu SMA (sebanyak 10 kelas). Pengambilan sampel dengan purposive sampling. Instrumen penelitian ini menggunakan tes soal kemampuan koneksi matematis dan skala kemandirian belajar.

Rumus yang digunakan untuk mengetahui ada tidaknya asosiasi antar kemampuan koneksi matematisa dan kemandirian belajar siswa adalah sebagai berikut (Sudjana, 2005)

$$
X^{2}=\sum_{i=1}^{B} \sum_{j=1}^{K} \frac{\left(\sigma_{i j}-e_{i j}\right)^{2}}{e_{i j}}
$$

\section{Keterangan}

B : Banyak baris

K : Banyak Kolom

$\sigma_{i j} \quad$ : frekuensi obsevasi pada baris ke-I, kolom ke-j

$e_{i j} \quad:$ frekuensi ekspetasi pada baris ke-I, kolom ke-j

Besarnya derajat asosiasi anatara kedua variabel dihitung dengan menggunakan rumus koefisen kontingensi $\quad C=\sqrt{\frac{X^{2}}{X^{2}+N}} \quad$ yang selanjutnya dibandingkan terhadap koefisien kontingensi maksimum $C_{\text {maks }}=\sqrt{\frac{m-1}{m}}($ Sudjana, 2005) dengan $\mathrm{m}$ adalah harga minimum banyaknya baris dan banyaknya kolom. Adapun klasifikasi derajat asosiasi dapat dilihat pada Tabel 2 berikut

Tabel 2. Koefisien Kontingensi

\begin{tabular}{|c|c|}
\hline $\begin{array}{l}\text { Koefisien } \\
\text { Kontingensi }\end{array}$ & Penggolongan \\
\hline $\mathrm{C}=0$ & $\begin{array}{l}\text { Tidak mempunyai } \\
\text { asosiasi }\end{array}$ \\
\hline $0 \leq \mathrm{C}<0,20$ & $\begin{array}{l}\text { Asosiasi rendah } \\
\text { sekali }\end{array}$ \\
\hline $\begin{array}{l}0,20 \mathrm{C}_{\text {maks }} \leq \mathrm{C}< \\
0,40 \mathrm{C}_{\mathrm{maks}}\end{array}$ & Asosiasi Rendah \\
\hline $\begin{array}{l}0,40 \mathrm{C}_{\text {maks }} \leq \mathrm{C}< \\
0,70 \mathrm{C}_{\text {maks }}\end{array}$ & Asosiasi Cukup \\
\hline $\begin{array}{l}0,70 \mathrm{C}_{\text {maks }} \leq \mathrm{C} \leq \\
0,90 \mathrm{C}_{\text {maks }}\end{array}$ & Asosiasi Tinggi \\
\hline $\begin{array}{l}0,90 \mathrm{C}_{\text {maks }} \leq \mathrm{C}< \\
\mathrm{C}_{\text {maks }}\end{array}$ & $\begin{array}{ll}\text { Asosiasi } & \text { Tinggi } \\
\text { Sekali } & \end{array}$ \\
\hline $\mathrm{C}=\mathrm{C}_{\text {maks }}$ & Asosiasi Sempurna \\
\hline
\end{tabular}

\section{HASIL PENELITIAN DAN PEMBAHASAN}

Pada penelitian ini tes kemampuan kemampuan koneksi matematis dilakukan sebanyak dua kali, yaitu pretest dan postest. Tes ini diberikan kepada kelompok eksperimen dan kelompok kontrol. Kelompok eksperimen memperoleh pembelajaran pendekatan open-ended dan kelompok kontrol memperoleh pembelajaran konvensional. Berikut disajikan data deskritif pada Tabel 2 
ISSN 2089-8703 (Print) Vol. 7, No. 2 (2018) 283-290

ISSN 2442-5419 (Online)

Tabel 3. Data Deskritif Kemampuan Koneksi Matematis serta Kemandirian Belajar Siswa Pada Kedua Pembelajaran

\begin{tabular}{|c|c|c|c|c|c|c|c|c|c|}
\hline \multirow{3}{*}{$\begin{array}{l}\text { Variabel } \\
\text { Matematis }\end{array}$} & \multirow{3}{*}{$\begin{array}{l}\text { Data } \\
\text { Stat }\end{array}$} & \multicolumn{8}{|c|}{ Pembelajaran } \\
\hline & & \multicolumn{4}{|c|}{ Pendekatan Open-Ended } & \multicolumn{4}{|c|}{ Konvensional } \\
\hline & & $\mathrm{N}$ & Pretes & Postes & $\langle\mathrm{g}\rangle$ & $\mathrm{n}$ & Pretes & Postes & $\langle\mathrm{g}\rangle$ \\
\hline \multirow{3}{*}{$\begin{array}{l}\text { Koneksi } \\
\text { Matematis } \\
(\text { KKoM) }\end{array}$} & $\bar{x}$ & 30 & 5,36 & 13,43 & 0,565 & 30 & 5,26 & 12,33 & 0,483 \\
\hline & & & $(26,8 \%)$ & $(67,15 \%)$ & & & $(26,3 \%)$ & $(61,65 \%)$ & \\
\hline & SD & & 4,215 & 3,008 & & & 3,864 & 2,821 & \\
\hline \multirow{3}{*}{$\begin{array}{l}\text { Kemndrian } \\
\text { Belajar } \\
(\mathrm{KBM})\end{array}$} & $r$ & 30 & & 75,8 & & 30 & & 67,13 & \\
\hline & & & - & $(67,67 \%)$ & - & & - & $(59,93 \%)$ & - \\
\hline & SD & & & & & & & 12,90 & \\
\hline
\end{tabular}

12,31

Skor ideal : $\mathrm{KBKfM}=20, \mathrm{KKoM}=20, \mathrm{KBM}=112$; KkoM: Kemampuan Koneksi Matematis

KBM: Kemandirian Belajar Siswa

$\begin{array}{ccc}\text { Berdasarkan Tabel } & 3 \text {, diperoleh } \\ \text { bahwa rats-rata } & \text { peningkatan }\end{array}$ kemampuan koneksi matematis siswa dengan pembelajaran pendekatan openended maupun pembelajaran konvensional memiliki kemampuan awal yang tidak jauh berbeda satu sama lain. Sedangkan hasil postes tersebut terlihat bahwa hasil rata-rata postes pada kemampuan koneksi matematis siswa dengan pembelajaran pendekatan open-ended lebih tinggi daripada ratarata postes kemampuan koneksi matematis siswa pada pembelajaran konvensional.
Kemudian hasil analisis skor postest kemandirian belajar menunjukkan bahwa kemandirian belajar yang mengikuti pembelajaran dengan pendekatan open-ended lebih baik dibanding yang mengikuti pembelajaran konvensional.

Untuk melihat apakah terdapat perbedaan yang signifikan tentang kemampuan koneksi matematis siswa setelah mengikuti pendekatan openended dan konvensional, maka dilakukan uji perbedaan rata-rata. Rangkuman hasil uji tersebut tertera dalam Tabel 4

Tabel 4. Uji Hipotesis Perbedaan Mean KKoM, N-Gain KKoM, dan KB pada Kedua Pembelajaran

\begin{tabular}{lcccccc}
\hline \multicolumn{1}{c}{ Variabel } & $\begin{array}{c}\text { Pendekatan } \\
\text { pembelajaran }\end{array}$ & Rerata & SD & N & Sig. & Interpretasi \\
\hline Koneksi & Open-Ended & 13.43 & 3.008 & 30 & 0.000 & KkoM $_{\text {Op }}>$ \\
Matematis & Konvensional & 12.33 & 2.821 & 30 & 0.000 & KkoM $_{\text {konv }}$ \\
N-Gain & Open-Ended & 0.565 & 0.120 & 30 & 0.000 & N-GAIN \\
Koneksi & Konvensional & 0.483 & 0.120 & 30 & 0.000 & $\mathrm{KkoM}_{\text {Op }}>$ N- \\
Matematis & & & & & & $\mathrm{GAIN} \mathrm{KkoM}_{\text {konv }}$ \\
Kemandirian & Open-Ended & 75.8 & 12.31 & 30 & 0.000 & $\mathrm{~KB}_{\text {Op }}>\mathrm{KB}_{\text {konv }}$ \\
Belajar & Konvensional & 67.13 & 12.90 & 30 & 0.000 & \\
\hline
\end{tabular}


Berdasarkan Tabel 4, pengujian hipotesis menggunakan uji statistik satu pihak (1-tailed) maka hasil nilai Sig. Pada output SPSS yaitu 0,000 dibagi dua $(0,0000 / 2)$ menghasilkan 0,000 . Hal ini menunjukkan nilai sig $<$ a yang berarti $\mathrm{H}_{0}$ ditolak dan dapat disimpulkan bahwa peningkatan kemampuan koneksi matematis siswa yang memperoleh pembelajaran pendekatan open-ended secara signifikan lebih baik daripada yang pembelajaran menggunakan konvensional pada taraf signifikasi $5 \%$. Hasil penelitian ini sesuai dengan temuan penelitian (Yaniawati, 2003, Gordah, 2012). Penelitian Yaniawati (2003) menemukan bahwa kemampuan koneksi matematis peserta didik tetapi belum mencapai kriteria hasil belajar yang baik. Penelitian Gordah (2012) pembelajaran matematika melalui pendekatan Open-Ended dapat memupuk kemampuan koneksi dan pemecahan masalah matematis peserta didik. Kemampuan koneksi matematis dengan kemampuan pemecahan masalah matematis hendaknya dalam pembelajaran saling berhubungan, karena koneksi merupakan bagian dari pemecahan masalah.

\section{Asosiasi antara Kualifikasi Koneksi Matematis dan kemandirian belajar Siswa}

Untuk melihat ada tidaknya asosiasi antara kualifikasi kemandirian belajar dan koneksi matematis siswa digunakan asosiasi kontingensi. Hasil penggolongan kualifikasi kemandirian belajar dan kemampuan berpikir koneksi matematis tersebut disajikan dalam Tabel 5

Tabel 5. Kontinensi Kemandirian Belajar dan Kemampuan Koneksi Matematis Siswa

\begin{tabular}{cccccc}
\hline \multirow{3}{*}{ Kemandirian } & & \multicolumn{4}{c}{ Kemampuan Koneksi matematis } \\
\cline { 3 - 6 } belajar & Tinggi & 10 & 0 & 0 & 10 \\
& Sedang & 2 & 5 & 0 & 7 \\
& Rendah & 0 & 1 & 12 & 13 \\
\hline Total & & 12 & 6 & 12 & 30 \\
\hline
\end{tabular}

Berdasarkan Tabel 5, diketahui terdapat 10 orang siswa yang memiliki kemandirian belajar dan koneksi tinggi; tidak ada siswa yang memiliki kemandirian belajar tinggi dan koneksi sedang dan rendah; 2 orang siswa yang memiliki kemandirian belajar sedang dan koneksi tinggi; 5 orang siswa yang memiliki kemandirian belajar sedang dan koneksi sedang; tidak ada siswa yang memiliki kemandirian belajar sedang dan koneksi rendah; tidak ada siswa yang memiliki kemandirian belajar rendah dan koneksi tinggi; 1 orang siswa yang memiliki kemandirian belajar rendah dan koneksi sedang; 12 orang siswa yang memiliki kemandirian belajar rendah dan koneksi rendah. Rangkuman hasil perhitungannya dapat dilihat pada Tabel 6

Tabel 6. Hasil Uji Chi-Square Kemandirian Belajar dan Kemampuan Koneksi Matematis

\begin{tabular}{llll}
\hline & \multicolumn{1}{c}{ Value } & Df & $\begin{array}{c}\text { Asymp. Sig. } \\
(2-\text { sided })\end{array}$ \\
\cline { 2 - 4 } Pearson Chi-Square & $42.363^{\mathrm{a}}$ & 4 & $\mathbf{. 0 0 0}$ \\
N of Valid Cases & 30 & & \\
\hline
\end{tabular}

288 | AKSIOMA 
Dari hasil perhitungan pada Tabel 6 diperoleh nilai sig $=0,000$ (Sig. $<0,05)$ dengan kata lain $\mathrm{H}_{0}$ ditolak. Sehingga dapat disimpulkan terdapat asosiasi yang signifikan antara kontingensi kemandirian belajar dan kemampuan koneksi matematis siswa pada taraf signifikansi $5 \%$.

Tabel 7. Kontingensi Kemampuan Koneksi dan Kemandirian Belajar

\begin{tabular}{ccc}
\hline \multicolumn{2}{c}{ Symmetric Measures } & Value \\
\hline Nominal by Nominal & $\begin{array}{c}\text { Contingency } \\
\text { Coefficient }\end{array}$ & $\mathbf{7 8 4}$ \\
N of Valid Cases & $\mathbf{3 0}$ \\
\hline
\end{tabular}

Pada Tabel 7 terlihat nilai koefisien kontingensi $\mathrm{C}=0,784$. Agar $\mathrm{C}$ dapat dipergunakan untuk menilai derajat asosiasi antara kedua variabel, maka harga $\mathrm{C}$ perlu dibandingkan dengan Cmak sebesar 0,816. Interpretasi atas nilai ini menunjukkan asosiasi antara kemampuan koneksi dan kemandirian belajar matematis siswa pada kelas eksperimen bernilai sangat signifikan. Artinya dengan adanya nilai ini cukup bisa menunjukkan bahwa siswa yang mempunyai peringkat atas pada skala kemandirian belajar ada kemungkinan juga akan menempati peringkat atas pada tes kemampuan koneksi matematis dan begitu juga sebaliknya. Temuan penelitian sesuai dengan penelitian Badjeber (2015) Terdapat asosiasi antara kemampuan koneksi matematis dan kemandirian belajar siswa yang memperoleh pembelajaran inkuiri model alberta.

\section{KESIMPULAN DAN SARAN}

Berdasarkan hasil analisis, temuan dan pembelajaran yang telah diuraikan pada sebelumnya dapat disimpulkan bahwa adanya pencapaian dan peningkatan kemampuan koneksi matematis siswa yang memperoleh pembelajaran pendekatan open-ended lebih baik daripada kemampuan koneksi matematis siswa yang memperoleh pembelajaran konvensional. Terdapat asosiasi antara kemampuan koneksi matematis dengan kemandirian belajar tergolong sangat kuat.

Berdasarkan simpulan tersebut dikemukan implikasi secara umum kemampuan koneksi matematis merupakan kemampuan yang sukar dimiliki siswa. Perlu adanya pengaruh guru dalam menggunakan pendekatan pembelajaran yang dapat meningkatkan kemampuan koneksi matematis. Selain itu juga, guru harus memberikan latihan soal yang sifatya tidak rutin, lebih bervariasi dengan menekankan taksonomi bloom. Kemandirian belajar siswa dengan menggunakan pendekatan open-ended masih tergolong kuat sedangkan pembelajaran konvensional tergolong sedang. disarankan kepada guru dapat mengembangkan kemandirian belajar siswa yang harus dilatih seperti guru menerapkan serta menanamkan pentingnya perilaku yang termuat dalam kemandirian belajar, guru dapat memberikan contoh kemandirian belajar dalam pebelajaran dikelas serta melaksanakan pembelajaran matematika yang terintegrasi dan berkelanjutan 


\section{DAFTAR PUSTAKA}

Abd., Qohar (2011). Asosiasi antara Koneksi Matematis dan Komunikasi Matematis Serta Kemandirian Belajar Matematika Siswa SMP. Prosiding Lomba dan Seminar Matematika (LSM) XIX Peran ICT untuk Mendukung Implementasi Pendidikan Karakter dalam Pembelajaran Matematika. Universitas Negeri Yogyakarta: ISSN 978-97917763-3-2

Badjeber, Rafiq. (2015). Penerapan pembelajaran Inkuiri Model Alberta Untuk Meningkatkan Kemampuan Penalaran, Koneksi Matematis dan kemandirian belajar Siswa SMP Studi Pada Salah Satu SMP di Kota Palu. Tesis Pasca Sarjana Universitas pendidikan Indonesia, Tidak diterbitkan. Bandung:PPs UPI.

Fleming, M. (2005). Adolescent Autonomy: Desire, Achievement and Disobeying Parents Between Early and Late Adolescence. Australian Journal of education and Developmental Psychology. Vol.5 hal.116

Gordah, E. (2012). Upaya Guru Meningkatkan Kemampuan Koneksi dan Pemecahan Masalah Matematis Peserta Didik Melalui Pendekatan Open-Ended. Jurnal Pendidikan dan Kebudayaan. [Online], 18 (3). Tersedia:

http://jurnaldikbud.kemdikbud.go.id/i ndex.php/jpnk/article/download/87/8 [18 Sepetember, 2018].

Isfayani, E., Johar, R., \& Munzir, S. (2018). Peningkatan Kemampuan Koneksi Matematis dan Self Efficacy Melalui Model Pembelajaran Kooperatif Tipe
Rotating Trio Exchange (RTE). Jurnal Elemen 4(1)

Muslich, Ina V.S. dkk. TIMSS. (2008). Internasional Mathematics Report. (TIMSS \& PIRLS : 2008)

Siagian, Muhammad Daut. (2016). Kemampuan Koneksi Matematik Dalam Pembelajaran Matematika. Journal of Mathematics Education and Science, 2 (1) ISSN : 2528-4363

Sudjana. (2005). Metoda Statistika. Bandung: Tarsito

Sumarmo, U. (2013). Kumpulan Makalah Berpikir dan Disposisi Matematika Berpikir Serta pembelajarannya. Bandung: Jurusan Pendidikan Matematika F-MIPA UPI.

Yaniawati, P. (2003), Pembelajaran dengan Pendekatan Open-Ended Dalam Upaya Meningkatkan Kemampuan Koneksi Matematika Siswa. Tesis pada PPs UPI: Tidak diterbitkan

Yuniawatika. (2011). Penerapan pembelajaran Matematika dengan Strategi REACT untuk Meningkatkan Kemampuan Koneksi dan Representasi Matematika Siswa Sekolah Dasar (Studi Kuasi Eksperimen di Kelas $V$ Sekolah Dasar Kota Cimahi). ISSN 1412-565X Edisi Khusus No.1 Agustus 2011 